\title{
Unusual subcutaneous mixed tumour exhibiting adipose, fibroblastic, and epithelial components
}

\author{
PS SMITH, J MCCLURE \\ From the Division of Tissue Pathology, Institute of Medical and Veterinary Science, Frome Road, Adelaide, \\ South Australia 5000
}

SUMMARY A subcutaneous mass in the left supraclavicular fossa of a 55-year-old woman proved on histological examination to be composed of islands of squamous cells embedded in bands of spindle cells and associated with mature adipose tissue. Electron microscopy showed that the spindle cells were fibroblastic in nature and not squamous cells showing spindle differentiation. There was also a minor lymphangiomatous component and sparse infiltrates of lymphoid cells. The lesion bore certain similarities to thymolipoma except that the presence of spindle cells and the site were atypical. While it may be speculated that the tumour was thymolipoma occurring in an ectopic cervical thymus the lesion is provisionally regarded as an unusual mixed tumour featuring mesenchymal and epithelial components.

The histopathological examination of a subcutaneous tumour removed from the left supraclavicular fossa revealed epithelial, fibroblastic, and mature adipose tissue components. Since descriptions of a similar entity could not be found in previous reports the results of histopathological and ultrastructural studies of this lesion are reported here. The possibility that the tumour represents an unusual thymolipoma occurring in an ectopic cervical thymus is discussed as is the classification of the lesion in a group of tumours referred to as nonmetastasising mixed tumours featuring adipose tissue and an epithelial component.

\section{Case report}

The patient was a 55-year-old woman who had been in good health. She presented with a lump in the left supraclavicular region which had apparently been present for many years and which had been growing slowly. A clinical diagnosis of lipoma was made and the lump was excised. It was lateral to the sternomastoid muscle and deep to the platysma. It was not related to the thyroid gland. The mass shelled out easily although it did dip down behind the clavicle a little. There appeared to be no extension to the thoracic cavity and there were no significant attachments. The deep aspect of the tumour was superfi- cial to the muscles of the neck and superficial to the vessels in the root of the neck. Chest $x$-ray revealed no evidence of mediastinal enlargement.

PATHOLOGICAL FEATURES

The tumour was a well circumscribed ovoid mass measuring $80 \times 50 \times 40 \mathrm{~mm}$ and weighing $85.5 \mathrm{~g}$. The cut surface was transected by bands of pale tissue bounding areas of typical adipose tissue (Fig. 1). Microscopically there was a discrete fibrous capsule. There was an intimate mixture of disparate elements (Fig. 2). There was a background of mature adipose tissue in which there were islands and strands of squamous epithelium. Occasionally these were lying free in adipose tissue, or in loose connective tissue (Fig. 3) or surrounded by a sparse lymphoid infiltrate (Fig. 4). The squamous cell components exhibited heratohyalin formation and occasionally cystic degeneration. Most frequently the islands of squamous cells lay in bands of spindle cells (Fig. 5) which transected the tumour and which corresponded to the bands of pale tissue seen macroscopically. Another microscopic feature was a lymphangiomatous component.

Portions of formalin-fixed tissue were post-fixed in osmium tetroxide and processed into Spurr's resin. Survey sections were cut and representative blocks were thin-sectioned for electron microscopy.

There were islands of cells separated from a collagen stroma by a basal lamina. These cells had mildly irregular nuclei with occasional nucleoli and 


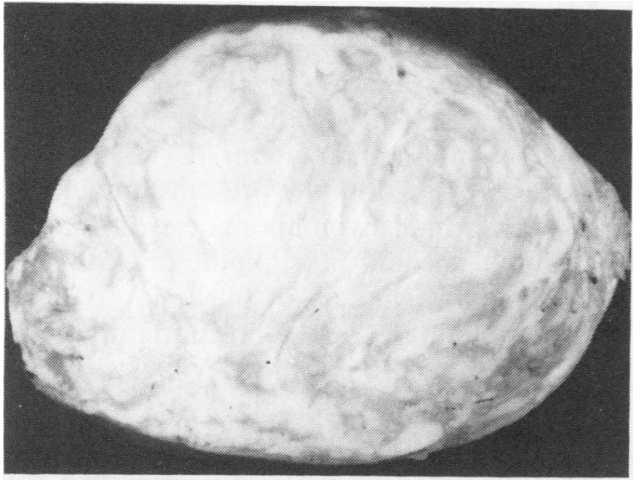

Fig. 1 Cut surface of the tumour showing adipose tissue transected by bands of pale tissue

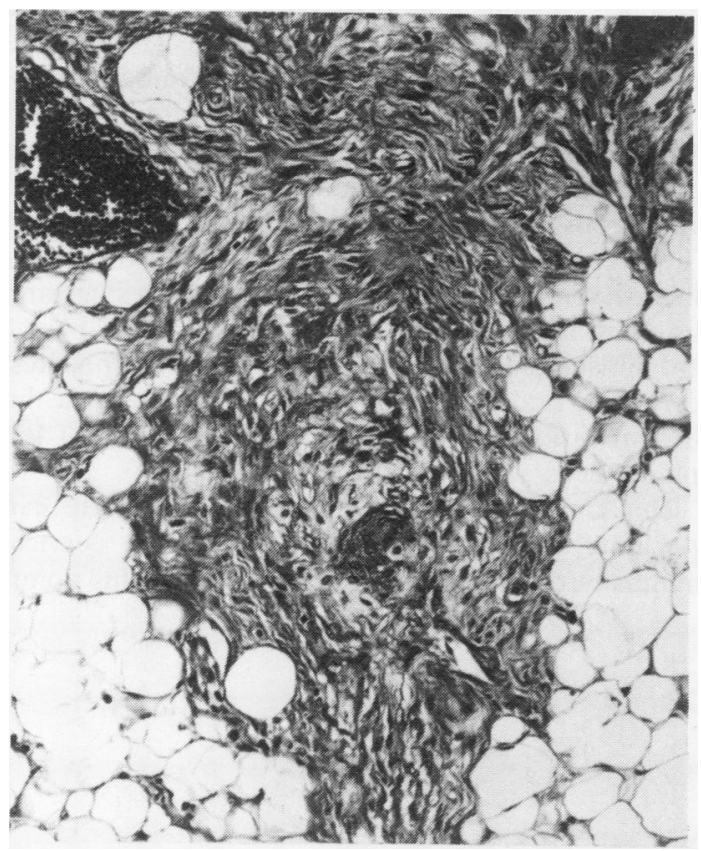

Fig. 2 Adipose tissue admixed with bands of spindle cells. There are squamous islands and a background vascularity. Haematoxylin and eosin $\times 120$

their cytoplasm contained small amounts of rough endoplasmic reticulum (RER), mitochondria, free ribosomes and tonofilaments. Desmosomes were also seen infrequently between cells (Fig. 6). In the stroma there were spindle-shaped cells with quite variable nuclear morphology ranging from regularovoid to convoluted, and containing occasional nucleoli. Their cytoplasm contained moderate amounts of RER and small numbers of mitochondria and free ribosomes (Fig. 7). The mature lipocytes were also seen, their cytoplasm was filled with a single large lipid droplet.

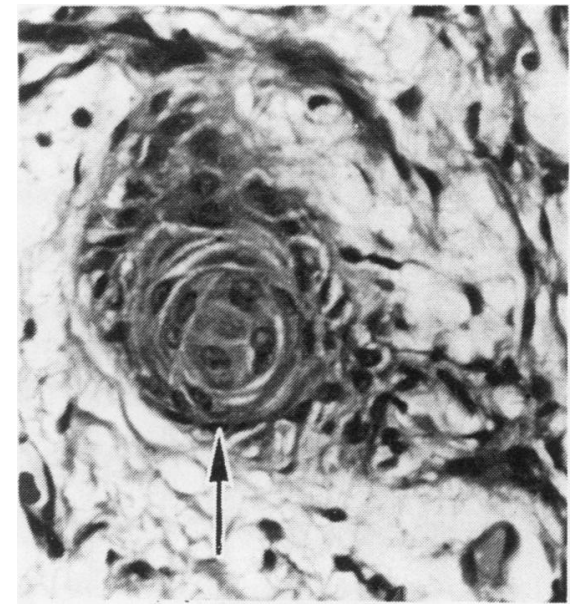

Fig. 3 Island of squamous epithelium (arrowed) embedded in loose connective tissue. Haematoxylin and $e \sin \times 200$

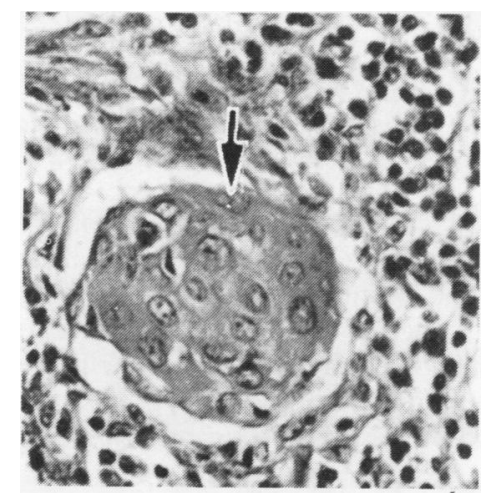

Fig. 4 Island of squamous epithelium (arrowed) surrounded by lymphocytes. Haematoxylin and eosin $\times$ 200

\section{Discussion}

This is a most unusual tumour and a description of a corresponding lesion has not been found in previous reports. It is a mixed tumour with mesenchymal, squamous and lymphangiomatous elements but without chondroid, Schwann cell or other differentiation. The total clinical and macroscopic features suggest that it is a discrete fatty tumour rather than a neoplasm infiltrating normal fat. In the differential diagnosis one must consider a mixed tumour of salivary gland origin, a sweat gland tumour and less likely a peculiar variant of one of the mixed tumours of the thyroid or parathyroid gland such as lipoadenoma of the parathyroid. Again the clinicoanatomical features of this case tend to rule out the latter possibilities as well as salivary and sweat gland tumours. One is therefore left with a 


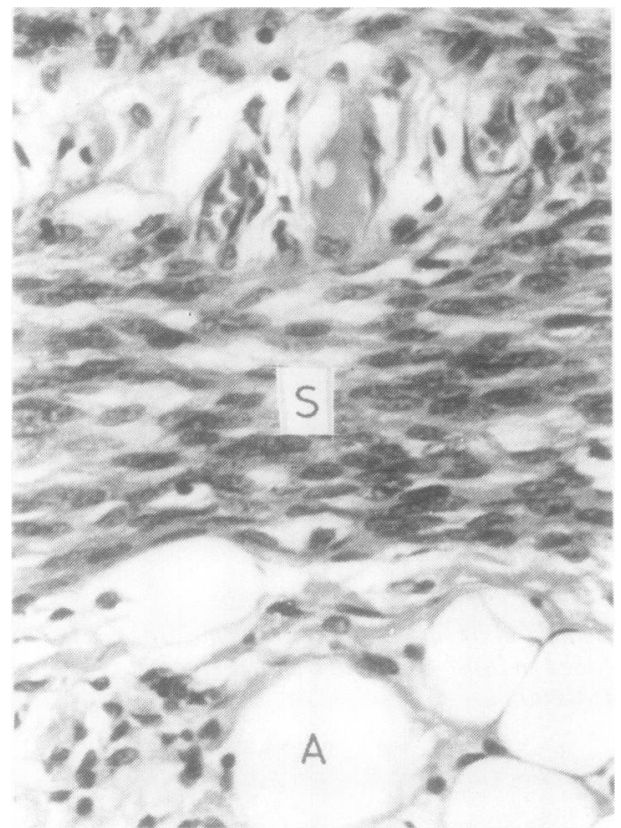

Fig. 5 Bands of spindle cells $(S)$ adjacent to mature adipose tissue $(A)$. Haematoxylin and eosin $\times 200$

tumour with a distinctive pattern of islands of squamous cells merging with spindle cells and set in a background of mature adipose tissue. The only tumour in which a majority of these features has been described is a thymolipoma. The presence of a lymphangiomatous component is also consistent with a thymolipoma since on one occasion several foci of cystic lymphangiomatous tissue were present in an otherwise typical thymolipoma. ${ }^{1}$ Thymolipoma is a comparatively rare tumour some 60 cases having been reported ${ }^{2}$ and it is said to comprise between $2 \%$ and $9 \%$ of all thymic tumours. ${ }^{3}$ The majority of the features exhibited by the present tumour would be consistent with a thymolipoma except that there is no available account of a spindle cell component in thymolipomas. The site of the lesion is unusual and there would appear to be no continuity with the mediastinum and neither is there evidence of a separate lesion in the mediastinum.

Ectopic thymic tissue may occur in the neck and the lesion may therefore be thymolipoma in an ectopic cervical thymus.

The electron microscopic findings confirms the presence of squamous cells (with desmosomes and tonofilaments) and mature lipocytes. The spindle cells did not contain desmosomes and tonofilaments. Their overall features were indicative of cells of a fibroblastic nature and not squamous cells showing spindle differentiation. The differentiation of white adipose tissue has been described by Napolitano. ${ }^{4}$ The presumptive precursors of lipoblasts are indistinguishable from fibroblasts in the earliest stage and differentiation takes place through early lipoblastic and midstage lipoblastic phases to mature lipocytes. Early and midstage lipoblasts were not seen in the present lesion and it is therefore unlikely that the spindle cells are presumptive lipoblasts.

This therefore is an unusual tumour. One can speculate about its origin in an ectopic cervical thymus but one cannot be categorical on this point.

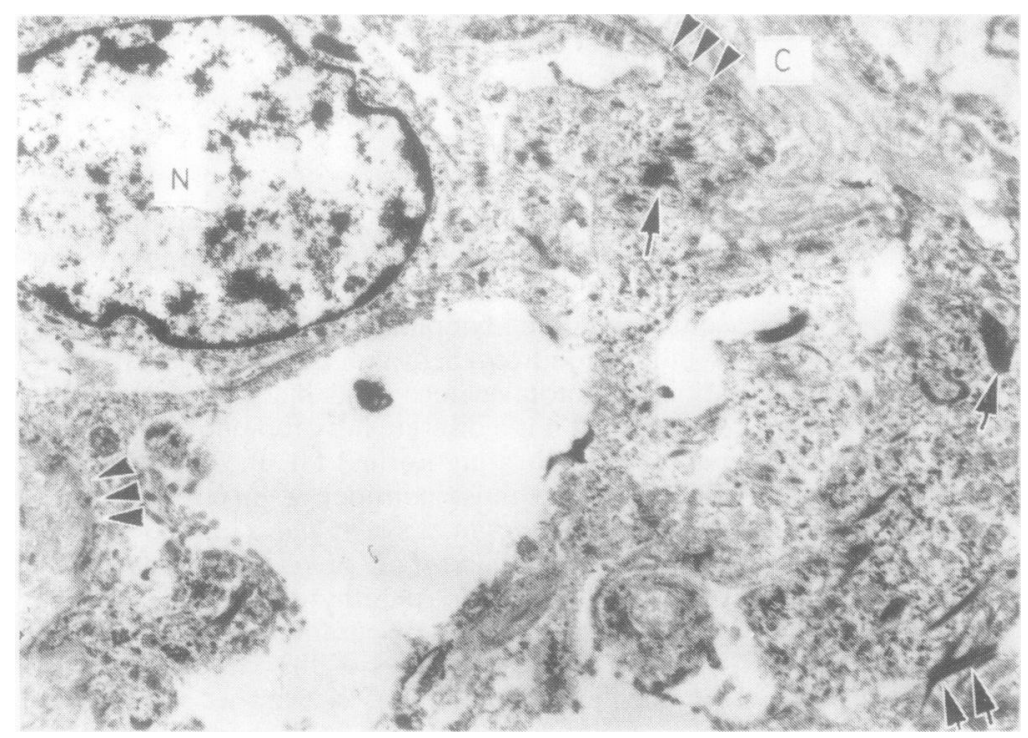

Fig. 6 Edge of a squamous island showing collagenous stroma (C), a mildly irregular nucleus $(N)$, tonofilaments (single arrows), a desmosome (double arrows) and basal lamina (triple arrows). $\times$ 6400 


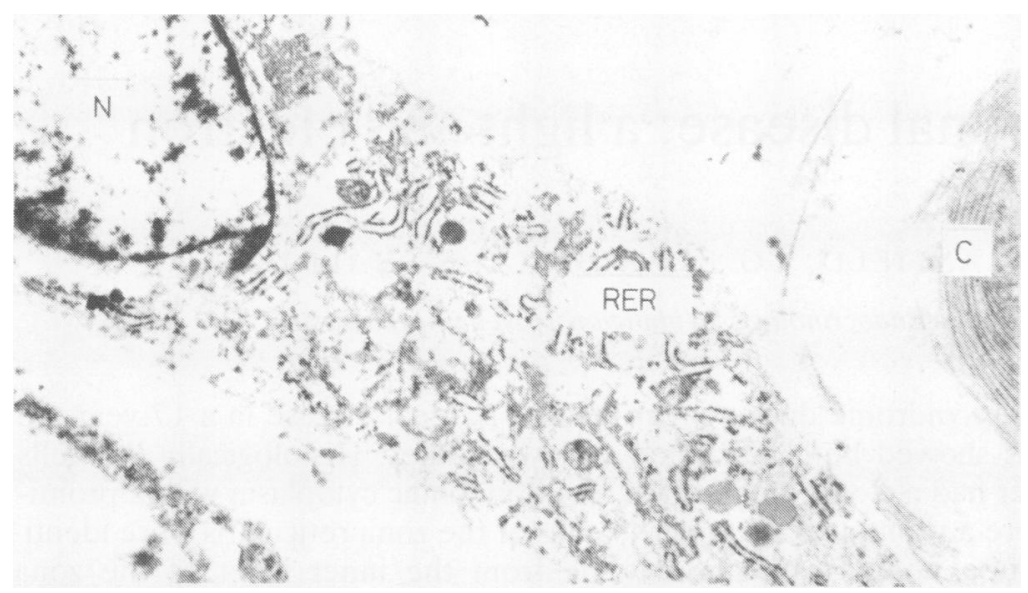

Fig. 7 Stromal cell showing a mildly irregular ovoid nucleus $(N)$ and prominent rough endoplasmic reticulum (RER). Note also the collagenous stroma $(C) . \times 6400$

The lesion is therefore best regarded as an unusual subcutaneous mixed mesenchymal tumour featuring adipose tissue, a spindle cell component and an epithelial component. It was well encapsulated, easily excised and there was no significant cellular pleomorphism or mitotic activity. The lesion is considered, on these grounds, to have a good prognosis.

The lesion may be another member of a group of neoplasms which are all rare and which have received little attention as a group. These are nonmetastasising mixed mesenchymal tumours featuring adipose tissue and an epithelial component. ${ }^{5}$ The tumours include thymolipoma, lipoadenoma of the parathyroid gland, ${ }^{6}$ thyrolipoma ${ }^{7}$ and mammary adenolipoma. The latter is regarded by Azzopardi ${ }^{8}$ as merely a lipoma which has incorporated lobular epithelial elements.

The precise nature of this group of tumours must be regarded as somewhat controversial. They may be true neoplasms, hamartomas or less likely, represent fatty degeneration in foci of parenchymatous hyperplasia. Probably the consensus of opinion would be that thymolipoma is a true neoplasm but a resolution of the precise nature of the other entities must await recognition and description of further examples of these rare lesions.
We wish to thank Mrs L Murray and Miss R Noble who cut the EM sections and Mrs C Wickremasuriya ior typing the manuscript.

\section{References}

' Scully NM. Lipothymoma with cystic lymphangioma: case report. Ann Surg 1960;26:400-4.

${ }^{2}$ Reintgen D, Fetter BF. Roses A, McCarty KS. Thymolipoma in association with myasthenia gravis. Arch Pathol Lab Med 1978;102:463-6.

${ }^{3}$ Rosai J, Levine GD. Tumours of the thymus. Washington DC: Armed Forces Institute of Pathology, 1976:162-6.

${ }^{4}$ Napolitano L. The differentiation of white adipose cells. An electron microscope study. J Cell Biol 1963;18:663-79.

${ }^{5}$ Allen PW. Tumours and proliferations of adipose tissue: a clinicopathological approach. New York: Masson Publishing USA Inc, 1981:75

${ }^{6}$ Abul-Haj SK, Conklin H, Hewitt WC. Functioning lipoadenoma of the parathyroid gland: report of a unique case. $N$ Engl $J$ Med 1962;266:121-3.

' Chesky VE, Dreese WC, Hellwig CA. Adenolipomatosis of the thyroid: a new type of goitre. Surgery 1953;34:38-45.

${ }^{8}$ Azzopardi JG. Problems in breast pathology. London: WB Saunders Co Ltd. 1979:396.

Requests for reprints to: Dr J McClure, Institute of Medical and Veterinary Science, PO Box 14, Rundle Street Post Office, Adelaide, South Australia 5000. 